University of Wollongong

Research Online

Faculty of Social Sciences - Papers (Archive) Faculty of Arts, Social Sciences \& Humanities

$1-1-2017$

\title{
Making versus observing manipulations of geometric properties of triangles to learn geometry using dynamic geometry software
}

\author{
Sahar Bokosmaty \\ University of Wollongong, saharb@uow.edu.au \\ Myrto F. Mavilidi \\ University of Wollongong, myrto@uow.edu.au \\ Fred Paas \\ University of Wollongong, Erasmus University Rotterdam, fredp@uow.edu.au
}

Follow this and additional works at: https://ro.uow.edu.au/sspapers

Part of the Education Commons, and the Social and Behavioral Sciences Commons

Research Online is the open access institutional repository for the University of Wollongong. For further information contact the UOW Library: research-pubs@uow.edu.au 


\title{
Making versus observing manipulations of geometric properties of triangles to learn geometry using dynamic geometry software
}

\author{
Abstract \\ Human movement has been found to have positive effects on learning performance. This study examined \\ the effects of using Dynamic Geometry Software (DGS) CABRI to manipulate geometric properties of \\ triangles or observing those manipulations made by an instructor on learning geometric properties with \\ DGS-CABRI. Participants were 60 year 5 students, who received instructions on geometric problems and \\ were randomly assigned to three conditions: A condition in which they performed mouse movements to \\ manipulate geometric properties of triangles, a condition in which they observed the teacher performing \\ those manipulations, and a conventional condition in which they studied a static format of the learning \\ materials without any manipulations. We hypothesized that learning conditions involving manipulations of \\ geometric properties of triangles would result in lower cognitive load and higher performance on a \\ retention and transfer test than the conventional condition. Moreover, we hypothesized that making \\ manipulations of the geometric properties of triangles through mouse movements would be superior to \\ observing those manipulations being made by an instructor in terms of cognitive load, retention- and \\ transfer test performance. Whereas the first hypothesis was confirmed, the latter hypothesis was only \\ confirmed for retention test performance. Possible implications for educational practice are discussed.

\section{Disciplines} \\ Education | Social and Behavioral Sciences

\section{Publication Details} \\ Bokosmaty, S., Mavilidi, M. \& Paas, F. (2017). Making versus observing manipulations of geometric \\ properties of triangles to learn geometry using dynamic geometry software. Computers and Education, \\ 113 313-326.
}




\section{Accepted Manuscript}

Making versus observing manipulations of geometric properties of triangles to learn geometry using dynamic geometry software

Sahar Bokosmaty, Myrto-Foteini Mavilidi, Fred Paas

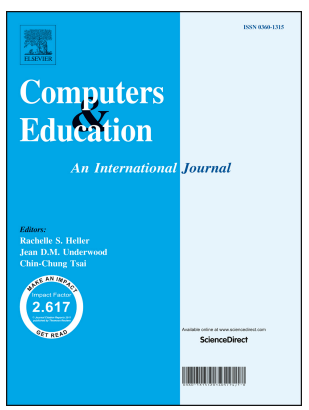

PII:

S0360-1315(17)30144-6

DOI:

10.1016/j.compedu.2017.06.008

Reference: $\quad$ CAE 3199

To appear in: Computers \& Education

Received Date: 14 February 2017

Revised Date: 6 June 2017

Accepted Date: 9 June 2017

Please cite this article as: Bokosmaty S., Mavilidi M.-F. \& Paas F., Making versus observing manipulations of geometric properties of triangles to learn geometry using dynamic geometry software, Computers \& Education (2017), doi: 10.1016/j.compedu.2017.06.008.

This is a PDF file of an unedited manuscript that has been accepted for publication. As a service to our customers we are providing this early version of the manuscript. The manuscript will undergo copyediting, typesetting, and review of the resulting proof before it is published in its final form. Please note that during the production process errors may be discovered which could affect the content, and all legal disclaimers that apply to the journal pertain. 
Making versus Observing Manipulations of Geometric Properties of Triangles to Learn Geometry using Dynamic Geometry software

\footnotetext{
Sahar Bokosmaty ${ }^{1}$, Myrto-Foteini Mavilidi ${ }^{1}$, and Fred Paas ${ }^{1,2}$

${ }^{1}$ Early Start Research Institute, University of Wollongong, Australia

${ }^{2}$ Department of Psychology, Education \& Child Studies, Erasmus University Rotterdam, The Netherlands
}

Author Note

Sahar Bokosmaty, Early Start Research Institute, Faculty of Social Sciences,

University of Wollongong, NSW 2522, Australia E-mail: $\underline{\text { saharb@uow.edu.au }}$ 
Making versus Observing Manipulations of Geometric Properties of Triangles to Learn Geometry using Dynamic Geometry software

\begin{abstract}
Human movement has been found to have positive effects on learning performance. This study examined the effects of using Dynamic Geometry Software (DGS) CABRI to manipulate geometric properties of triangles or observing those manipulations made by an instructor on learning geometric properties with DGS-CABRI. Participants were 60 year 5 students, who received instructions on geometric problems and were randomly assigned to three conditions: A condition in which they performed mouse movements to manipulate geometric properties of triangles, a condition in which they observed the teacher performing those manipulations, and a conventional condition in which they studied a static format of the learning materials without any manipulations. We hypothesized that learning conditions involving manipulations of geometric properties of triangles would result in lower cognitive load and higher performance on a retention and transfer test than the conventional condition. Moreover, we hypothesized that making manipulations of the geometric properties of triangles through mouse movements would be superior to observing those manipulations being made by an instructor in terms of cognitive load, retention- and transfer test performance. Whereas the first hypothesis was confirmed, the latter hypothesis was only confirmed for retention test performance.

Possible implications for educational practice are discussed.
\end{abstract}


Keywords: manipulation, dynamic geometry software, learning geometry, properties of triangles, cognitive load theory

Cognitive load theory (CLT; Paas, Renkl, \& Sweller, 2003; Sweller, 1988; Sweller, Van Merrienboer, \& Paas, 1998) stresses the importance of effective instructional design taking into account the relationship between the cognitive load imposed by the learning task and environment and the human cognitive architecture (Paas, Renkl, \& Sweller, 2003; Sweller, Ayres, \& Kalyuga, 2011; Sweller \& Sweller, 2006). Cognitive load is considered as the amount of working memory capacity that is actually allocated by the learner to accommodate the demands of the learning task and environment (Choi, Van Merrienboer, \& Paas, 2014; Paas \& Van Merrienboer, 1994a). The human cognitive architecture includes a very large long-term memory for storing information (i.e., the information store principle) with most of that information obtained from other people (i.e., the borrowing and reorganizing principle), a random generator for creating novel information (i.e., the randomness as genesis principle), a severely limited working memory, both in capacity (Baddeley, 1986; Cowan, 2001) and duration (Peterson \& Peterson, 1959), for dealing with novel information (i.e., the narrow limits of change principle), and a connection between long-term memory and working memory that eliminates the limitations of working memory (i.e., the environmental organizing and linking principle; Sweller, \& Sweller, 2006). Using this cognitive architecture, cognitive load theory can contribute to the design and delivery of educational experiences advocating that learning can occur through observation and imitation of what others say, do, or write (Paas \& Sweller, 2012; Sweller 2004; Sweller \& Sweller, 2006). 
CLT has used Geary's (2002, 2007a, 2007b, 2008, see also Sweller, 2008) evolutionary description of educational psychology to indicate two categories of knowledge: Biologically primary knowledge is information we have evolved to acquire such as learning to listen and speak our native language or learning to use general problem solving strategies. This type of knowledge can be acquired without explicit instruction and used effortlessly, and consequently it does not impose a cognitive load. In contrast, biologically secondary knowledge involves skills that are more difficult to assimilate and require explicit instruction and effort in order to be acquired. Based on this evolutionary account of cognitive load, Paas and Sweller (2012) have argued that it may be advantageous to use primary information to assist in the acquisition of secondary information. The content that is taught in educational institutions, such as perception of mathematical and science concepts, including the geometry subject matter of the current paper constitutes biologically secondary knowledge. During learning of geometry, the use of worked-out examples that show the steps needed to solve a problem, can contain biologically primary information in the form of movement to enhance students' problemsolving skills, facilitating schema construction, rule automation, and transfer of learning (Bokosmaty, Kalyuga, \& Sweller, 2015; Paas, \& Van Merriënboer, 1994b).

\section{The Human Movement Effect}

As argued by Paas and Sweller (2012), evolutionary perspectives on educational psychology can lead to further cognitive load theory effects, such as the human movement effect. They argued that human movement can be considered biologically primary knowledge, which does not impose a significant working memory load. According to Paas and Sweller (2012) this knowledge can be used to facilitate the 
learning of biologically secondary knowledge (Paas \& Sweller, 2012). The human movement effect (Ayres, Marcus, Chan, \& Qian, 2009; Wong, Marcus, Ayres, Smith, Cooper, Paas, \& Sweller, 2009) is one of the current CLT effects in which learning materials including human movements that can either be made or observed by the learner seem not to be affected by limited working memory capacity. For example, it has been argued by cognitive load theorists that when dynamic visualizations impose a high extraneous cognitive load, they are not effective for learning (Ayres \& Paas, 2007a, b; Paas, Van Gerven, \& Wouters, 2007). The cause of this load can be a result of several factors and characteristics of the instruction. A split-attention effect can be caused by separating texts from diagrams (e.g., Ayres \& Sweller, 2005; Chandler \& Sweller, 1992; Mayer \& Moreno, 1998). The transitory feature of dynamic visualizations has been identified as another factor that imposes extraneous cognitive load. Information in dynamic visualizations, such as animations, is only shortly visible, and after it has disappeared new information must be processed and integrated with previous information to learn from the animation (Hegarty, 2004; Lewalter, 2003).

However, when teaching human psychomotor skills, the use of dynamic visualizations has proven to be valuable for students' learning. For these skills, which include both cognition and movement, the tension between a limited working memory and the nature of transient information does not seem to exist when animated rather than static diagrams are used. A meta-analysis by Höffler and Leutner (2007) showed that animations generally lead to better learning when they are related to real life and when motor skills are engaged. Van Gog, Paas Marcus, Ayres, and Sweller (2009; Ayres \& Paas, 2009) also argued that the load created by the transient aspect of dynamic visualization could be reduced when human movement could be observed. The authors 
suggested that this might be due to the "mirror-neuron system" (Rizzolatti \& Craighero, 2004), which is a neural system in the brain that is automatically activated when observing movements made by someone else, thereby supporting mental simulation and imitation of these movements.

The argument that learners can benefit from observing and following models are favored by two recent studies. Firstly, a study of Wong and colleagues (2009), in which primary school students had to learn origami skills. Secondly, a study of Ayres and colleagues (2009), in which college students had to learn how to tie a knot and finish puzzles. The outcomes of both studies indicated that instructional animations that foster motor skills are superior to the equivalent static graphics. The human movement effect suggests that acquiring biologically secondary information can be facilitated by employing biologically primary knowledge. Even though information that is changing can pose a working memory load when using dynamic representations, the load can be reduced when human movement that is related to biologically primary skill is involved (Paas \& Sweller, 2012).

\section{Embodied cognition perspective}

According to the theoretical framework of embodied cognition, conceptual representations are grounded in different modalities, i.e., perceptual, motor, emotional (Barsalou, 2008). The sensorimotor experiences arising from the environment play a paramount role in learning (Wilson, 2002). It is believed that movements can expand the working memory capacity, which is particularly effective for more complex learning tasks that require more working memory resources. According to Glenberg (2010) perception and how memory works is affected by how people move their bodies. To that 
vein, $\mathrm{Hu}$, Ginns, and Bobis (2015) suggested that pointing and tracing gestures might enhance geometry learning by activating an 'increased working memory channel'. Learning might be enhanced by using multiple processing channels (visual, auditory and haptic). For instance, Hu and colleagues $(2014,2015)$ examined tracing effects on paperbased worked examples of geometry and arithmetic operations in a series of experiments. Results revealed higher learning outcomes in the tracing conditions, in which students were able to trace the angle relationships, or arithmetic symbols and brackets involved in the symbols, compared to a visual control condition, in which students only looked at the worked-examples.

Agostinho et al. (2015) examined the effects of pointing and tracing on learning temperature line graphs through an Ipad application in primary school children from 8 to 11 years. Students were enrolled either in the trace condition, in which they had to trace the information to-be-learned with their index finger, or the non-trace condition, in which they only looked at the same information. During learning, they studied workedexamples and afterwards they answered similar test questions about temperature line graphs, and more complex transfer test questions. Results showed that students in the trace condition performed better on the transfer test questions than the students in the non-trace condition.

Most of the existing research examining the effects of making movements, has been focused on making gestures in learning of abstract concepts (i.e., math). However, along with making, observing movements also can have a positive effect on learning. For instance, teachers' gestures can be used by students as an additional resource for understanding new mathematical concepts (Cook \& Goldin-Meadow, 2006; Roth, 2001). It was found that when children observed gestures related to an abstract mathematical 
concept (e.g., equalizer strategy), they tended to imitate these gestures. The production of gestures helped them to better understand the problem-solving strategy accompanying these gestures and the given instructions, and eventually to solve math problems correctly (Cook \& Goldin-Meadow, 2006). Finally, Cook, Duffy, and Fenn (2013) studied how gesture observation can influence second to fourth grade children's learning and maintenance of mathematics. Participants were assigned either to the speech only or speech and gesture condition. During training, children in the speech and gesture condition watched videos containing gestures while the videos in the speech condition did not. Afterwards, they were asked to solve abstract problems that are similar to those shown in the videos. Students' performance was evaluated on an immediate post-test, a delayed post-test after 24-hr, and a transfer test. Results revealed that the gesture and speech condition performed better and showed improvements from the immediate posttest to the delayed post-test. Observing gestures seemed to have a strong effect on initial learning but also on transfer of learning, allowing for consolidation of the acquired knowledge.

\section{Gesture-based Educational Technology in Geometry}

Current literature emphasises the role of gestures as semiotic tools, contributing to deeper understanding of mathematical concepts (Arzarello \& Edwards, 2005). A recent systematic review assessed the effects of touch-based educational technology, which included the use of tablets in learning (Agostinho, Ginns, Tindall-Ford, Mavilidi, \& Paas, 2016). The studies included comparisons of single versus multiple finger gestures, tap and dragged used on an iPad versus physical manipulation of the task, finger pointing on a touchscreen versus mouse use, finger gestures and transformation of geometric shapes 
("shearing"), and tapping, pointing versus pinching. The conclusions reflect on the tenet that finger-based gestures can support learning outcomes.

The interaction between the teacher and the students is fundamental for effective instruction of geometry (Yu, Barrett, \& Presmeg, 2009). According to Vistro-Yu (2009), several innovative techniques can be applied to generate problems in mathematics education. These techniques focus on problem replacement (i.e., posing the same problem but changing the units, shapes), contextualizing the problem to make it more relevant to students, or addition (i.e., posing the same problem but adding a new constraint or obstacle). The use of technology during mathematics instruction such as interactive geometry software, enables the construction of figurative, operational, and relational prototypes, and gives the flexibility to learners and instructors to engage in these techniques, resulting in higher-level thinking, better problem-solving skills, understanding and reasoning about two-dimensional shapes (Battista 2002; Yu, 2004, 2009). For instance, the dynamic geometry systems offer the opportunity to swipe finite and infinite points, as well as connect figures (Karaibryamov, Tsareva, \& Zlatanov, 2013). Apart from saving time from drawing work, these options help to identify invariant relations, and generalize problems and their solutions. The dynamic geometry systems offer a new approach of teaching for very difficult geometry tasks (see for example "The mutual intersecting of pyramids and prisms in axonometry", Karaibryamov, Tsareva, \& Zlatanov, 2012).

The following research examines the effects of dynamic geometry environments on geometry learning. Firstly, a study by Chang, Sung, and Lin (2007) developed a geometry software to engage second-grade students of an elementary school in different activities (e.g., "jigsaw puzzle, shape tracer, stamping, arranging matchsticks, shadow 
matching, identifying cards"). Children were enrolled either to the experimental condition (using the geometry software) or control condition. It was found that the experimental condition had better learning outcomes on visual association, description/analysis, abstraction/relation, and overall geometry thinking.

Vitale, Swart, and Black (2014) introduced digital geometry software for learning defining features of shapes, namely parallel lines, congruent adjacent sides, and right angles to third and fourth grade students. Students in the grounded integrated condition (GI) were presented with animated models of hand gestures showing geometrical concepts. Students were able to manipulate these visual representations. Students in the numerical integrated condition (NI) were provided with a numerical display of the same novel spatial concepts. Students' ability on identifying shapes (e.g., trapezoids, parallelograms, rhombi, isosceles triangles/trapezoids, rectangles, and right triangles) was evaluated at a paper-based pre-test and a computer-based post-test. It was found that the GI condition had higher accuracy scores than the NI. It was concluded that the introduction of novel grounding metaphors in the form of gestural depictions offered the students a deeper understanding of the conceptual representations of the features.

Finally, previous research has investigated the role of Dynamic Geometry Software (DGS) on developing deductive reasoning in geometry (i.e., internalize concepts and use of proofs and proving during problem-solving) in twenty-eight twelvegrade students (Jones, 2000). The instruction focused on classifying quadrilaterals. The first phase of the 9-month study included familiarization with the Cabri software, whereas in the next phases students constructed quadrilaterals (i.e., rhombus, square, and kite), and worked on the relationships between these shapes (i.e., rhombus and square). Qualitative analysis from videos and audio tapes revealed that students developed the 
sense of underlying relationships between the geometric properties, being able to give solid, precise explanations entirely linked to the mathematical context. Mariotti (2001) conducted a two-year study in $9^{\text {th }}$ and $10^{\text {th }}$ grade students on implementing the Cabri software into the mathematics instructions. Qualitative data showed that the Cabri environment through dragging, along with the significant teachers' contribution, helped students to build their geometrical understanding and heuristics.

Dragging practices in Cabri contribute to cognitive shifts from theory to practice, allowing perceptions to build upon theoretical lenses (Arzarello, Olivero, Paola, \& Robutti, 2002). Dragging supports the production of real "explanations" or conjectures or properties, giving feedback during the discovery phase, by looking at ways after drawings have changed (or not) forms and allowing to discover the invariant properties. For instance, students can be engaged in different dragging modalities (i.e., wandering dragging, guided dragging, line dragging, linked dragging) to achieve different goals such as exploring, conjecturing, or validating.

The current study

Based on the literature discussed above, it can be concluded that the learning process is highly engaged with action in the form of gestures. Cognitive load theory has suggested that involving body movements (i.e., biologically primary knowledge) in learning of complex cognitive tasks (i.e., biologically secondary knowledge) might reduce the learners' working memory load and positively affect learning performance. In addition, research on DGS has provided evidence for its positive effects on geometry learning. Combining both research lines, it would be interesting to investigate the effects of using DGS to manipulate learning materials. Therefore, this study will examine the 
effect of making and observing manipulations of geometric properties of triangles made by mouse movements ("drag") of the students themselves or the teacher on student's learning of geometry (i.e., the sum of measures of angles in a triangle: See also Bokosmaty et al., 2015). The movements were either made by the students or by the instructor with the use of DGS CABRI, which is commercial software for teaching and learning geometry and trigonometry (Vincent, 1999). The program allows the user to animate geometric figures, proving a significant advantage over those drawn on a board (Vincent, 1999). It further permits an exploration of the properties of geometry objects and their relationships. The relationships between points on a geometric object may easily be demonstrated, which can be useful in the learning process (Straesser, 2002).

In the manipulation condition, students could use the mouse to manipulate a specific angle or side to find the measure of the other angles or sides in a triangle. In the observing manipulation condition, students watched the instructor manipulating a specific angle or side to find the measure of the other angles or sides in a triangle. In the conventional learning condition, students were given the measure of a specific angle or side and the instructor provided the students with the measure of the other angles or sides in a triangle. Among others, Goldin-Meadow et al. (2012) have shown that learners perform better when action is involved, and concluded that students are better able to learn when they make gestures themselves than when they observe someone else's gestures. Thus, it was hypothesized that involving learners in manipulations of geometric properties of triangles, either by making those manipulations themselves through mouse movements or by observing a teacher making those manipulations would result in lower cognitive load and higher learning performance than presenting the manipulations in 
static format (i.e., in the conventional condition). In addition, it was hypothesized that making manipulations would lead to lower cognitive load and higher learning performance than observing manipulations.

\section{Method}

\section{Participants}

The participants were 60 year 5 students (30 females; aged between 10 and 11) attending a private school with relatively high SES background in a major Australian city. The school divides the students into three ability groups (low, intermediate and high) according to their performance in the mathematics examinations in the previous year (year 4). The students were chosen randomly from the intermediate ability group class. The grading of students by class teachers according to their mathematical skills is standard practice and part of the curriculum in the school. The topic chosen for this experiment was included in the year 5 mathematical program of this school, but was not given to the students before the time of the experiment.

Students were exposed to two 45-min sessions about the sum of measures of angles in a triangle and the names of special triangles (isosceles, equilateral, etc.), and two 45min sessions on software training. Students were randomly assigned to the three conditions, in such a way that each condition contained 20 students (10 males and 10 females). In the first experimental, 'manipulation' condition participants were presented with a given triangle and were instructed by the researcher to manipulate a specific angle or side by placing the cursor on the assigned angle or side then dragging it with the use of the computer mouse in order to move the triangle. In the other experimental, 'observing 
manipulation' condition, participants were presented with the same given triangle and watched the researcher making the manipulations (dragging the angle or side with the use of the computer mouse) of a specific angle or side. The cursor appeared as a hand icon on the screen of the computer (see Figure 1) for both conditions. Participants in the control condition learned in the conventional way by studying static pictures demonstrating the measure of the corresponding angle or side.

\section{Materials}

The instruction in the learning phase consisted of the Dynamic Geometry software and paper-based materials. CABRI, is a dynamic geometry software (see Figure 1) for drawing and animating geometric figures (Vincent, 1999). Students were presented with four geometric problems based on two types of triangles. The selected triangles were isosceles triangles and equilateral triangles. These triangles form part of the mathematics curriculum materials suitable for students in year 5. None of the participants had any experience with the individual figures forming these triangles. The four problems were related to examining the changes of the measure of angles/sides compared to changes of the measure of the sides/angles of the given triangle. In each problem, students were given the measure of the three angles and the measure of the three sides and were guided to recognize the changes of the measure of the angles/sides with respect to changes to the measure of the sides/angles. The three groups were presented with the same triangle (same measure of angles and same measure of sides; see Figure 2), and the researcher gave the same verbal instructions to the participants in the three conditions. The 
reproduced figures were identical in size, including angle size, and retained the same angle name, for each figure category (see Figure 3).

In the observing manipulation condition, the researcher manipulated a specific angle of the given triangle (that has three different measures of angles and three different lengths of sides), until the three angles were equal to $60^{\circ}$ each (see Figure $3 a$ ). The identical figure was used in the manipulation condition, but learners were instructed to manipulate the same specific angle of the same given triangle by using the mouse and were instructed to stop when the three angles showed the same measures, hence they stopped when the three angles were $60^{\circ}$ each. Participants in the conventional learning condition were given a print out of the same given triangle as the other conditions and also the reproduced figure that showed a triangle with three equal sides and three equal angles, each measure $60^{\circ}$ (see Figures $2 \& 3$ a). Students were instructed in the three conditions to visualize and note that the three sides are with the same measure of length with three equivalent angle measures. A discussion was conducted in the three conditions about the measure of the sides of any given triangle compared to the measure of its angles, highlighting the fact that when the three sides of any given triangles are equal, then the three angles will have equal measures and each will be equal to $60^{\circ}$. The other three problems were presented using the same methods for the three conditions but aimed to allow students to recognize and note that in any given triangle, if the three sides are equal then the three angles will be equal (see Figure 3b) if two sides are equal then two angles will be equal (see Figure 3c), and if two angles are equal then two sides are equal (see Figure 3d). 
Six problems were used in the paper-based test, which required calculating angles or sides of a given triangle. It consisted of three similar problems and three transfer problems. The similar problems were almost identical to the learning phase problems, with exactly the same figure as in the learning phase but with a different measure of the given angle or side (see Appendix A). The transfer problems were similar to the learning phase problems but the direction of the position of the triangle was changed. Thus, the given angle or side, was in different position than in the corresponding learning problems. Furthermore, learners were asked to prove certain sides or angles to be equal, rather than only calculating the measure of angles, which is another modification to the learning phase problems (see Appendix B).

\section{Procedure}

The experiment consisted of a learning phase (60 minutes) and a test phase (45 minutes). It was conducted over one school session, and each child was tested individually. A week prior to the experiment, four lessons were presented (45 minutes each) to all year 5 students. Two lessons were allocated to teach them the prerequisite knowledge that was needed to learn for the experimental materials. The required prior knowledge included the geometric terminology and properties used in the experiment (i.e., sum of measures of angles in a triangle is $180^{\circ}$, isosceles triangle has two equal sides and two equal angles, equilateral triangle has three equal sides and three equal angles). A sheet was distributed to students containing the properties taught. The other two lessons were assigned to train the students about the Cabri Geometry software. The instructor provided several figures (not related to the experimental problems) in order to facilitate mastery learning on the use of the software. Participants were told that there 
would be no specific time limit for learning, and the instructor took care that everyone mastered the software at the end of the lesson. The participants were then randomly assigned to one of the three instructional groups.

During the learning phase, students in each group were presented with the four problems described above in the materials section. Students were asked to work on each problem until they understood it. The instructor checked for each student whether he/she understood the problems. If students did not achieve the required answer, they were asked to try again till they accomplish the answer. Furthermore, the researcher checked students' work on an individual basis, and provided the correct solution and explanation for each problem before moving to the next problem.

A test phase immediately followed the learning phase. Since each problem had three solution steps, the test score was determined by allocating up to 3 marks for each test problem. With three problems, the lowest score that participants could achieve in the similar test was 0 and the highest score was 9 . One mark was allocated for a correct solution step. Thus, 3 marks were allocated for a correct task solution. The transfer test score was determined using the same marking system as the similar test problems, providing a score ranging from 0-9 for each participant.

Each problem was presented on a separate sheet of paper (see Appendices A and B). Participants were asked to provide written solutions. They were asked to work as rapidly and as accurately as possible. Students who finished the test in less than the allocated time (45 $\mathrm{min}$ ), were asked to review their work until the time expired to make sure that all students took the same time for each task. No feedback during the test phase 
was given to participants until after the experiment had been completed. The sheets used during the pre-learning phase were not available to participants during the test phase.

Immediately after the learning phase, participants were asked to estimate how easy or difficult it was for them to learn the material and answer the questions. According to Paas (1992; see also Ayres, 2006; Paas, Tuovinen, Tabbers, \& Van Gerven, 2003) these subjective ratings of mental effort or task difficulty can be used as reliable and valid measures of overall cognitive load (Paas, Van Merriënboer, \& Adam, 1994). This is evidenced by a range of studies revealing high internal consistency and sensitivity of the rating scale (for an overview see, Paas, Tuovinen, Tabbers, \& Van Gerven, 2003). In this study, similar to Paas (1992), a one-dimensional, 9-point symmetrical category Likerttype scale was used with numerical and verbal labels ranging from '1, extremely easy' to '9, extremely difficult' (see Appendix C).

\section{Results}

Variables. The dependent variables under analysis were similar and transfer test scores, and subjective ratings of cognitive load. The independent variable was instructional condition (conventional learning, manipulation, and observing manipulation). Eta-squared $\eta^{2}$ was used as an estimate of effect size, with $\eta^{2}=.02$ corresponding to a small effect, $\eta^{2}=.13$ corresponding to a moderate effect, and $\eta^{2}=.26$ corresponding to a large effect (Cohen, 1988, 2013).

Similar test results. A one-way analysis of variance (ANOVA) indicated a significant difference between the experimental conditions on the similar test scores, $F(2$, 
$57)=13.62, M S E=1.33, p=.001, \eta_{p}{ }^{2}=0.32$. According to Scheffé's HSD post-hoc test, the manipulation condition significantly outperformed the conventional learning condition, $p<.001$, and the observing manipulation condition, $p<.05$. There was also a significant difference between the observing manipulation condition and the conventional learning condition, $p<.05$, indicating that the observing manipulation condition outperformed the conventional learning condition. Means and standard deviations are provided in Table 1.

Transfer test results. An ANOVA indicated a significant difference between the experimental conditions on the transfer test scores, $F(2,57)=11.23, M S E=1.15, p<$ $.001, \eta_{p}{ }^{2}=0.28$. According to Scheffé's HSD post-hoc test, the manipulation condition significantly outperformed the conventional learning condition, $p<.001$. The observing manipulation condition significantly outperformed the conventional learning condition, $p$ $<.05$. However, there was no significant difference between the observing manipulation condition and the manipulation condition, $p=.17$. Means and standard deviations are provided in Table 1.

Ratings of cognitive load during learning. An ANOVA indicated a significant difference between the experimental conditions on the ratings of cognitive load, $F(2,57)$ $=12.19, M S E=1.73, p<.001, \eta_{p}{ }^{2}=0.30$. According to Scheffé's HSD post-hoc test, the manipulation condition significantly demonstrated a lower cognitive load rating than the conventional learning condition, $p<.001$, and the observing manipulation condition, $p<$ .05. There was no significant difference between the observing manipulation condition 
and the conventional learning condition, $p=.11$. Means and standard deviations are provided in Table 1.

\section{Discussion}

The present study investigated whether making manipulations of geometric properties of triangles by students through mouse movements or observing those manipulations made by an instructor would enhance students' learning of geometric properties. Previous literature attests that the significant advantage of diagrams in geometry is the connection of the theoretical objects with their graphical -spatial properties, contributing to better conceptual thinking (Laborde, 1999, 2002). Importantly, the meditational role of dynamic geometry software is accentuated, involving the interaction of these diagrams along with students' physical perceptions, motions, gestures and languages, that led to better understanding and production of conceptual explanations (Arzarello et al., 2002; Jones, 2000). In fact, the results of this study confirmed the hypothesis that learning conditions involving manipulations of geometric properties of triangles, either made by students through mouse movements or made by a teacher and observed by the students, resulted in lower cognitive load and higher performance on a retention and transfer test than a conventional learning condition without manipulations. The hypothesis that making manipulations through mouse movements would be superior to observing manipulations was only confirmed for retention test performance, but not for transfer test performance and cognitive load. The fact that we found significant differences between conditions for both the test performance and cognitive load measures, with large effect sizes, despite a small sample size, tends to indicate that the differences were also practically significant. As is common in research using this scale, 
the differences between conditions were rather small, with mean scores varying between 3 and 5 on a 9-point scale. However, the differences were also in the expected direction and previous research has shown that the ratings on this scale have a high internal consistency (Cronbach's alpha > .90; for an overview see Paas, Tuovinen, Tabbers, \& Van Gerven, 2003). Therefore, we believe that the current results are also significant from a practical point of view.

There is ample evidence that under certain conditions learning of cognitive tasks can be supported by observing or making manipulations. Paas and Sweller (2012) have proposed that this human movement effect (Ayres et al., 2009; Wong et al. 2009) can materialise because observing or making manipulations are evolutionarily salient skills that can be processed with relatively low working memory load, and consequently enable more novel information to be processed within the limited capacity working memory. In addition, Wong et al. (2009) have proposed a possible human movement working memory processor that evolved to learn from animations containing a human movement component. This proposal is in line with Baddeley's (2012) revised working memory model, which includes haptic sensory information (for example, kinesthetic and tactile input) that might affect information processing in the visuo-spatial sketchpad. It could be argued that learning that involved multiple modalities (modality effects, see Mousavi, Low, \& Sweller, 1995; Tindall-Ford, Chandler, \& Sweller, 1997) might expand the working memory capacity for learning difficult tasks.

In this study we used the evolutionary explanation to argue that the movements that needed to be made in this experiment represent a form of biologically primary knowledge that may have supported the construction of biologically secondary 
knowledge (for example, learning geometric rules) by reducing cognitive load. The learning activities that involved moving a learner's hand might also activate a haptic sensory modality that expanded the working memory capacity for a better learning performance. The results of the current study supported the effectiveness of the manipulation conditions over the non-manipulation control condition. The evolutionarily cognitive load explanation of this superiority is supported by the more favorable relationship between the cognitive load ratings of the learning phase and the performance scores of the test phase in the movement conditions than in the control condition, and more specifically in the manipulation condition than in the observing manipulation condition. However, it should be noted that our measurement of cognitive load through ratings of perceived difficulty can only reflect an overall estimate of cognitive load. Therefore, it is not clear what the level of cognitive demand from the various modalities, such as the cognitive and motor modality, was. For future research it is important to find a functional metric that can be used for measuring the cognitive demand from the various modalities. Such a metric could also provide evidence for the evolutionary inspired assumptions of cognitive load imposed by biologically primary and secondary knowledge.

Moreover, the results of this study are consistent with previous literature, suggesting that learning of geometry tasks is facilitated when these tasks are spatiallygrounded. Under the lens of the embodied cognition framework, novel information can be translated to a form of action where learners can perform an embodied representation of the action (Vitale, Swart, \& Black, 2014). The use of suitable instructional manipulatives is essential for learning abstract relations such as worked examples on 
learning geometry (Bokosmaty et al., 2015), providing the learner with rich learning environments embedded in sensorimotor experiences (Pouw, Van Gog, \& Paas, 2014). De Koning, and Tabbers (2013) found that observing a moving human hand in dynamic animations can improve learning compared to studying the animation with a pointing arrow. The moving hand ameliorates the mental representations, grounding the animation's movements into the learner's motor system. Observing animations that include human movements might help learning since, in accordance with the "mirrorneuron system", the observation of human movements can activate the neurons required for the execution of these movements (Fadiga, Fogassi, Pavesi, \& Rizzolati, 1995; Van Gog et al., 2009).

Finally, in compliance with previous literature, the role of lesson structure and student control is stressed during teaching with technology (Hollebrands \& Zbiek, 2004). It can be argued that, via the use of interactive geometry software, students' understanding and reasoning about two-dimensional shapes can be enhanced (Battista, 2002). The use of the computer for designing geometrical shapes (e.g., common types of quadrilateral and triangles) entails instructional activities such as dragging the square's vertices, resulting in changing the size and orientation but not the shape (Battista, 1998, 2002). In the current study, the use of movements ("dragging") facilitated students to divide the triangle into several parts, guiding them in the analysis of the spatial relationships of these parts, and fostering their understanding and learning (Battista, 2002; Chang et al., 2007). Thus, the results of this study can also be linked with van Hiele's levels of children's geometrical thinking (1986). These levels are the following: shape recognition (i.e., identification of geometrical shape), visual association (i.e., 
recognition of types of geometric shapes), description or analysis (i.e., relationships of sides and angles), abstract or relation (i.e., meaningful categorization and logical thinking of shapes), and formal axiomatic (i.e., verification, induction, inference of geometric principles). Overall, the Cabri software embodies Euclidean geometry with its elements and properties (such as intersecting lines and circles). Through dragging in Cabri software, students were able to identify the hierarchical relationship of the elements of the triangles, focusing on reflecting on the procedure by which they were built (Mariotti, 2001).

In fact, when comparing learning using static pictures (the conventional learning condition) and learning using dynamic representations (experimental conditions), learners in the conventional condition might have perceived the three different positions of triangles as three different triangles rather than one triangle that was presented in the dynamic condition (i.e., making the movement condition and observing the movement condition). The benefit of dynamic geometry systems is that the sketch can be presented on the screen, in which dynamic transformations occur throughout the presentation showing at the same time the preserved properties, without the need to be redrawn again (Karaibryamov et al., 2013). Thus, students in the making manipulation condition might have been more actively involved in the learning. Therefore, future studies should try to disentangle the effects of manipulations of objects through mouse movements and involvement, or specifically look into the relationship between both measures. Furthermore, learning in the static representations might have higher need for mental integration than the dynamic representations and thus impose higher demands on a learner's working memory capacity as several static pictures might have created more 
split attention and therefore needed more mental integration. The results of the current study provide support for this hypothesis as the lower levels of perceived difficulty (mental effort ratings) in both dynamic conditions is consistent with the cognitive load explanation.

In sum, we have found that involving students in manipulations of geometric properties of triangles either through making those manipulations through mouse movements or by observing them being made by a teacher has a bigger effect on learning than the conventional static method without manipulations, a finding that is parallel to other research on doing vs. seeing action (e.g., Cook, Duffy, \& Fenn, 2013; Cook \& Goldin-Meadow, 2006). Our findings thus flag the way for involving students with making object manipulation through mouse movement or observing those manipulations being made in educational settings to enhance geometric learning.

Overall, this study works in adjunction with current research on dynamic geometry systems in the classroom, facilitating learning and the understanding of geometry. The dynamic geometry systems present opportunities for deeper understanding, optimize the education process by saving time for drawing, generalizing large groups of problems, stimulating and assisting investigations, and forming a creative style of mathematical thinking (Karaibryamov et al., 2013). As such, it is recommended that these systems are included in the classrooms settings for more efficient teaching methods and higher learning outcomes. 


\section{References}

Agostinho, S., Tindall-Ford, S., Ginns, P., Howard, S. J., Leahy, W., \& Paas, F. (2015). Giving learning a helping hand: Finger tracing of temperature graphs on an iPad. Educational Psychology Review, 27, 427-443.

Agostinho, S., Ginns, P., Tindall-Ford, S., Mavilidi, M. F., Paas, F. (2016). 'Touch the screen': Linking touch-based educational technology with learning - a synthesis of current research. In L. Lin and R. Atkinson (Eds.), Educational technologies: Challenges, applications and learning outcomes, (pp. 33-57). New York: Nova Science Publishers.

Arzarello, F., \& Edwards, L. (2005). RF02 Gesture and the construction of mathematical meaning. In PME Conference (Vol. 29, No. 1, p. 1).

Arzarello, F., Olivero, F., Paola, D., \& Robutti, O. (2002). A cognitive analysis of dragging practises in Cabri environments. Zentralblatt für Didaktik der Mathematik, 34(3), 66-72.

Ayres, P. (2006). Using subjective measures to detect variations of intrinsic cognitive load within problems. Learning and Instruction, 16, 389-400.

Ayres, P., Marcus, N., Chan, C., \& Qian, N. (2009). Learning hand manipulative tasks: When instructional animations are superior to equivalent static representations. Computers in Human Behavior, 25, 348-353.

Ayres, P., \& Paas, F. (2007a). Making instructional animations more effective: A cognitive load approach. Applied Cognitive Psychology, 21, 695-700.

Ayres, P., \& Paas, F. (2007b). Can the cognitive-load approach make instructional animations more effective? Applied Cognitive Psychology, 21, 811-820. 
Ayres, P., \& Paas, F. (2009). Interdisciplinary perspectives inspiring a new generation of cognitive load research. Educational Psychology Review, 21, 1-9.

Ayres, P., \& Sweller, J. (2005). The split-attention principle in multimedia learning. In R. E. Mayer (Ed.), The Cambridge Handbook of Multimedia Learning (pp. 135-146). New York: Cambridge University Press.Barsalou, L. W. (2008). Grounded cognition. Annual Review of Psychology, 59, 617-645.

Baddeley, A. D. (1986). Working memory. Oxford, England: Oxford University Press. Baddeley, A. (2012). Working memory: Theories, models and controversies. Annual Review of Psychology, 63, 1-29.

Battista, M. T. (1998). Shape Makers: Developing geometric reasoning with the geometer's sketchpad. Berkeley, Calif.: Key Curriculum Press. Software.

Battista, M. T. (2002). Learning geometry in a dynamic computer environment. Teaching Children Mathematics, 8, 333-339.

Bokosmaty, S., Sweller, J., \& Kalyuga, S. (2015). Learning geometry problem solving by studying worked-examples: Effects of learner guidance and expertise. American Educational Research Journal, 52, 307-333.

Chandler, P., \& Sweller, J. (1992). The split-attention effect as a factor in the design of instruction. British Journal of Educational Psychology, 62, 233-246.

Chang, K. E., Sung, Y. T., \& Lin, S. Y. (2007). Developing geometry thinking through multimedia learning activities. Computers in Human Behavior, 23, 2212-2229.

Choi, H. H., Van Merrienboer, J. J. G., \& Paas, F. (2014). Effects of the physical environment on cognitive load and learning: Towards a new model of cognitive load. Educational Psychology Review, 26, 225-244. 
Cohen, J. (1988). Statistical power analysis for the behavioral sciences (2nd ed.). Hillsdale: Erlbaum.

Cohen, J. (2013). Statistical power analysis for the behavioral sciences. Routledge Academic.

Cook, S. W., Duffy, R. G., \& Fenn, K. M. (2013). Consolidation and transfer of learning after observing hand gesture. Child Development, 84, 1863-1871.

Cook, S. W., \& Goldin-Meadow, S. (2006). The role of gesture in learning: Do children use their hands to change their minds?. Journal of Cognition and Development, 7 , 211-232.

Cowan, N. (2001). The magical number 4 in short-term memory: a reconsideration of mental storage capacity. Behavioral and Brain Sciences, 24, 87-114.

De Koning, B. B., \& Tabbers, H. K. (2013). Gestures in instructional animations: A helping hand to understanding non- human movements? Applied Cognitive Psychology, 27, 683-689.

Fadiga, L., Fogassi, L., Pavesi, G., \& Rizzolatti, G. (1995). Motor facilitation during action observation: a magnetic stimulation study. Journal of Neurophysiology, 73, $2608-2611$.

Geary, D. C. (2002). Principles of evolutionary educational psychology. Learning and Individual Differences, 12, 317-345.

Geary, D. C. (2007a). Educating the evolved mind: Conceptual foundations for an evolutionary educational psychology. In J. S. Carlson \& J. R. Levin (Eds.), Psychological Perspectives on Contemporary Educational Issues (pp. 1-99). Greenwich, CT: Information Age. 
Geary, D. C. (2007b). Educating the evolved mind: Reflections and refinements. In J. S. Carlson \& J. R. Levin (Eds.), Psychological Perspectives on Contemporary Educational Issues (pp. 1-99). Greenwich, CT: Information Age.

Geary, D. C. (2008). An evolutionarily informed education science. Educational Psychologist, 43, 179-195.

Glenberg, A. M. (2010). Embodiment as a unifying perspective for psychology. WIREs Cognitive Science, 1, 586-596.

Goldin-Meadow, S., Levine, S. C., Zinchenko, E., Yip, T. K., Hemani, N., \& Factor, L. (2012). Doing gesture promotes learning a mental transformation task better than seeing gesture. Developmental Science, 15(6), 876-884.

Hegarty, M. (2004). Dynamic visualizations and learning: Getting to the difficult questions. Learning and Instruction, 14, 343-351.

Höffler, T. N., \& Leutner, D. (2007). Instructional animation versus static pictures: A meta-analysis. Learning and Instruction, 17, 722-738.

Hollebrands, K., \& Zbiek, R. M. (2004). Teaching mathematics with technology: An evidence-based road map for the journey. In R. N. Rubenstein \& G. Bright (Eds.), Perspectives on the teaching of mathematics: Sixty-sixth yearbook (pp. 259-270). Reston, VA: National Council of Teachers of Mathematics, Inc.

Hu, F.-T., Ginns, P., \& Bobis, J. (2014). Does tracing worked examples enhance geometry learning? Australian Journal of Educational \& Developmental Psychology, 14, 45-49.

Hu, F., Ginns, P., \& Bobis, J., (2015). Getting the point: Tracing worked examples enhances learning. Learning and Instruction, 35, 85-93. 
Jones, K. (2000). Providing a foundation for deductive reasoning: Students' interpretations when using dynamic geometry software and their evolving mathematical explanations. Educational Studies in Mathematics, 44, 55-85.

Karaibryamov, S. Tsareva, B., \& Zlatanov, B., (2012). Educational software for interactive training of students on the theme "Mutual intersecting of pyramids and prisms in axonometry", Acta Didactica Napocensia 5, 29-44.

Karaibryamov, S. Tsareva, B., \& Zlatanov, B., (2013). Optimization of the courses in geometry by the usage of dynamic geometry software. The Electronic Journal of Mathematics and Technology 7, 22-51.

Laborde, C. (1999). Core geometrical knowledge for using the modelling power of geometry with Cabri-Geometry. Teaching Mathematics \& its Applications, 18(4), $166-171$.

Laborde, C. (2002). Integration of technology in the design of geometry tasks with CabriGeometry. International Journal of Computers for Mathematical Learning, 6(3), 283-317.

Lewalter, D. (2003). Cognitive strategies for learning from static and dynamic visuals. Learning and Instruction, 13, 177-189.

Mariotti, M. A. (2001). Justifying and proving in the Cabri environment. International Journal of Computers for Mathematical Learning, 6(3), 257-281.

Mayer, R. E., \& Moreno, R. (1998). A split-attention effect in multimedia learning: Evidence for dual processing systems in working memory. Journal of Educational Psychology, 90, 312-320. 
Mousavi, Y., Low, R., \& Sweller, J. (1995). Reducing cognitive load by mixing auditory and visual presentation modes. Journal of Educational Psychology, 87 (2), 319334.

Paas, F. (1992). Training strategies for attaining transfer of problem solving skill in statistics: A cognitive load approach. Journal of Educational Psychology, 84, 429434.

Paas, F., Renkl, A., \& Sweller, J. (2003). Cognitive load theory and instructional design: Recent developments. Educational Psychologist, 38, 1-4

Paas, F., \& Sweller, J. (2012). An evolutionary upgrade of cognitive load theory: Using the human motor system and collaboration to support the learning of complex cognitive tasks. Educational Psychology Review, 24, 27-45.

Paas, F., Tuovinen, J., Tabbers, H., \& Van Gerven, P. (2003). Cognitive load measurement as a means to advance cognitive load theory. Educational Psychologist, 38, 63-71.

Paas, F., Van Gerven, P., \& Wouters, P. (2007). Instructional efficiency of animation: Effects of interactivity through mental reconstruction of static key frames. Applied Cognitive Psychology, 21, 783-793.

Paas, F., \& Van Merriënboer, J. J. G. (1994a). Instructional control of cognitive load in the training of complex cognitive tasks. Educational Psychology Review, 6, 5171.

Paas, F., \& Van Merriënboer, J. J. G. (1994b). Variability of worked examples and transfer of geometrical problem-solving skills: A cognitive-load approach. Journal of Educational Psychology, 86, 122-133. 
Paas, F., Van Merriënboer, J. J G., \& Adam (1994). Measurement of cognitive load in instructional research. Perceptual and Motor Skills, 79, 419-430.

Peterson, L. R., \& Peterson, M. J. (1959). Short-term retention of individual verbal items. Journal of Experimental Psychology, 58, 193-198.

Pouw, W. T., Van Gog, T., \& Paas, F. (2014). An embedded and embodied cognition review of instructional manipulatives. Educational Psychology Review, 26(1), 5172.

Rizzolatti, G., \& Craighero, L. (2004). The mirror-neuron system. Annual Review of Neuroscience, 27, 169-192.

Roth, W. M. (2001). Gestures: Their role in teaching and learning. Review of Educational Research, 71(3), 365-392.

Sweller, J., Ayres, P., \& Kalyuga, S. (2011). Measuring cognitive load. In Cognitive load theory (pp. 71-85). Springer New York.

Sweller, J. (1988). Cognitive load during problem solving: Effects on learning. Cognitive Science, 12, 257-285.

Sweller, J. (2004). Instructional design consequences of an analogy between evolution by natural selection and human cognitive architecture. Instructional Science, 321, 931.

Sweller, J. (2008). Instructional implications of David C. Geary's evolutionary educational psychology. Educational Psychologist, 43, 214-216.

Sweller, J., \& Sweller, S. (2006). Natural information processing systems. Evolutionary Psychology, 4, 434-458.

Sweller, J., Van Merriënboer, J. J. G., \& Paas, F. (1998). Cognitive architecture and instructional design. Educational Psychology Review, 10, 251-296. 
Straesser, R. (2002), Cabri-géomètre: Does Dynamic Geometry Software (DGS) Change Geometry and its Teaching and Learning? International Journal of Computers for Mathematical Learning, 6(3), 319-333.

Tindall-Ford, S., Chandler, P., \& Sweller, J. (1997). When two sensory modes are better than one. Journal of Experimental Psychology: Applied, 3, 257-287.

Yu, P., Barrett, J., \& Presmeg, N. (2009). Prototypes and categorical reasoning: A perspective to explain how children learn about interactive geometry objects. In T. V. Craine \& R. Rubenstein (Eds.), Understanding geometry for a changing world, 71st yearbook (pp. 109-125). Reston, VA: National Council of Teachers of Mathematics.

Yu, P.W. (2004). Prototype development and discourse among middle school students in a dynamic geometric environment. Ph.D. thesis, Illinois State University.

Van Gog, T., Paas, F., Marcus, N., Ayres, P., \& Sweller, J. (2009). The mirror-neuron system and observational learning: Implications for the effectiveness of dynamic visualizations. Educational Psychology Review, 21, 21-30.

Van Hiele, P. M. (1986). Structure and insight: A theory of mathematics education. Orlando, FL: Academic Press.

Vincent, J. (1999). Exploring 2-Dimensional Space: Cabri Geometry II for Years 9-12. Brunswick, Vic.: Mathematical Association of Victoria.

Vistro-Yu, C. P. (2009). Using innovation techniques to generate 'new' problems. In Mathematical Problem Solving: Yearbook 2009, Association of Mathematics Educators (pp. 185-207). World Scientific. 
Vitale, J. M., Swart, M. I., \& Black, J. B. (2014). Integrating intuitive and novel grounded concepts in a dynamic geometry learning environment. Computers \& Education, 72, 231-248.

Wong A., Marcus, N., Ayres, P., Smith, L., Cooper, G. A., Paas, F., \& Sweller, J. (2009). Instructional animations can be superior to statics when learning human motor skills. Computers in Human Behavior, 25, 339-347.

Wilson, M. (2002). Six views of embodied cognition. Psychonomic Bulletin \& Review, 9, 625-636. 
Table 1

Means and Standard Deviations for Similar and Transfer Test Scores, Ratings of

Cognitive Load

\begin{tabular}{|c|c|c|c|}
\hline $\begin{array}{l}\text { Instructional } \\
\text { Condition }\end{array}$ & Manipulation & $\begin{array}{c}\text { Observing } \\
\text { Manipulation } \\
n=20\end{array}$ & $\begin{array}{l}\text { Conventional } \\
\text { Learning } \\
n=20\end{array}$ \\
\hline \multicolumn{4}{|c|}{ Total Scores for Similar Test } \\
\hline$M$ & 7.30 & 6.35 & 5.40 \\
\hline$S D$ & 0.86 & 1.04 & 1.47 \\
\hline \multicolumn{4}{|c|}{ Total Scores for Transfer Test } \\
\hline$M$ & 6.10 & 5.45 & 4.50 \\
\hline$S D$ & 0.97 & 0.89 & 1.32 \\
\hline \multicolumn{4}{|c|}{ Ratings of Cognitive Load } \\
\hline$M$ & 2.95 & 4.10 & 5.00 \\
\hline$S D$ & 0.83 & 1.21 & 1.75 \\
\hline
\end{tabular}

Note: The maximum score was 9 for the similar test, the transfer test, and the ratings of cognitive load. 


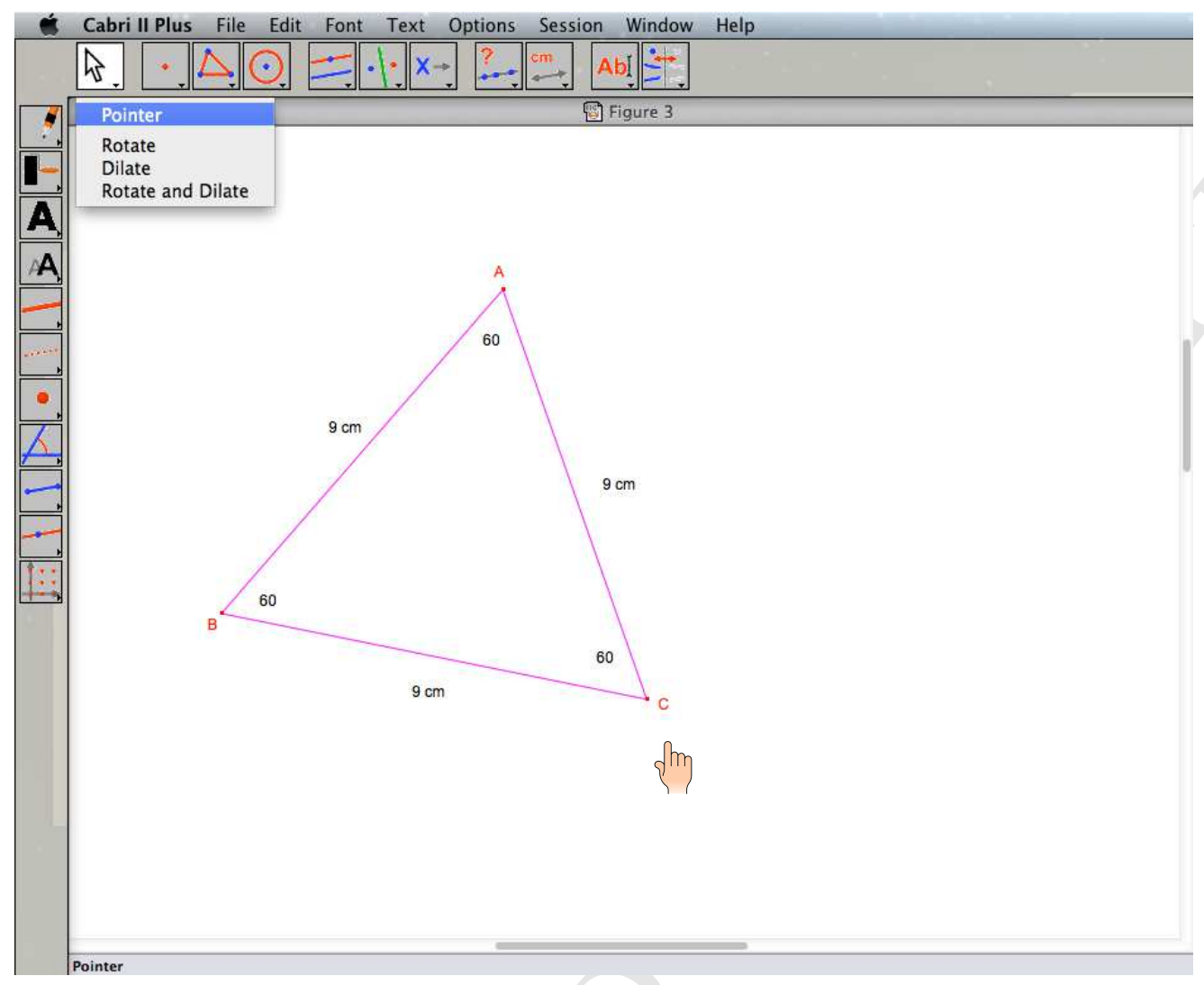

Figure 1

Example of Cabri Software drawings 


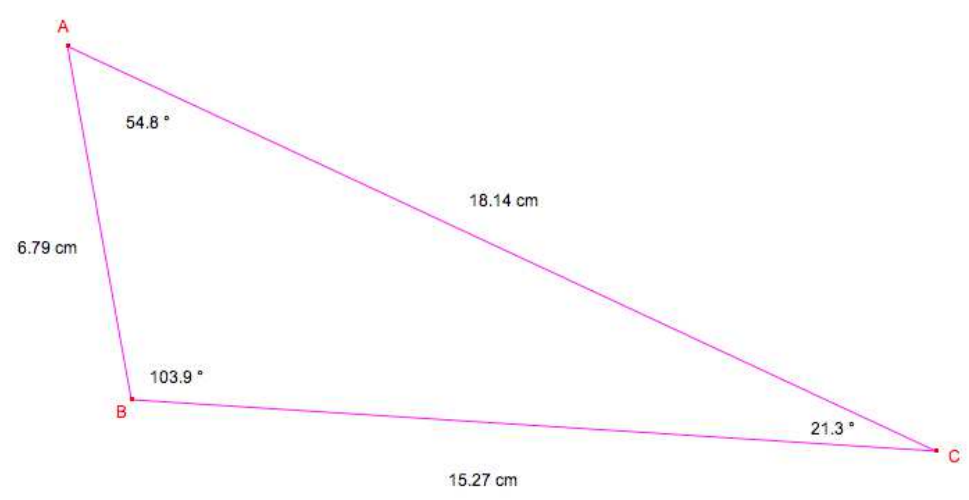

Figure 2. A triangle with three different sides and three different angles 


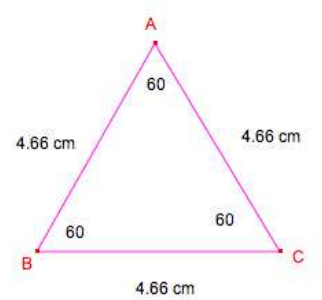

a. Recognize the length of sides when the three angles measures 60 each

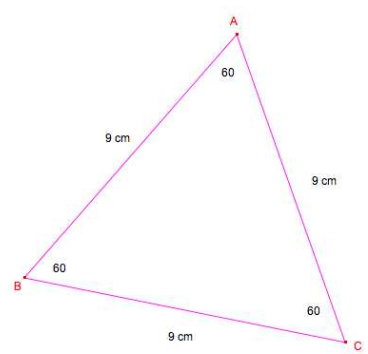

b. Recognize the measure of angles when the three sides have the same length, each $9 \mathrm{~cm}$

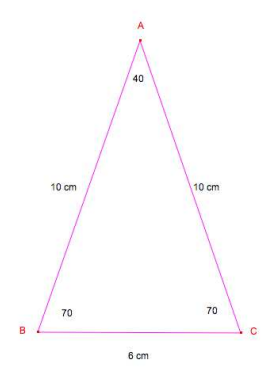

c. Recognize the measure of the base angles when two sides of a triangle have the same length, each $10 \mathrm{~cm}$

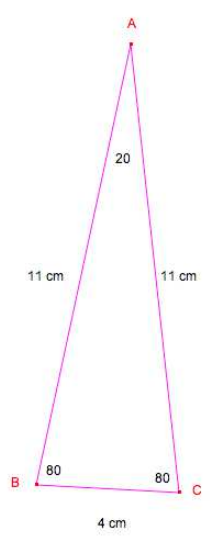

d. Recognize the measure of the two sides of a triangle when the two base angles have the same measure, each 80

Figure 3. Examples of instructions about the triangles used in the different conditions 
Appendix A

Similar Test Material

Similar test problem 1

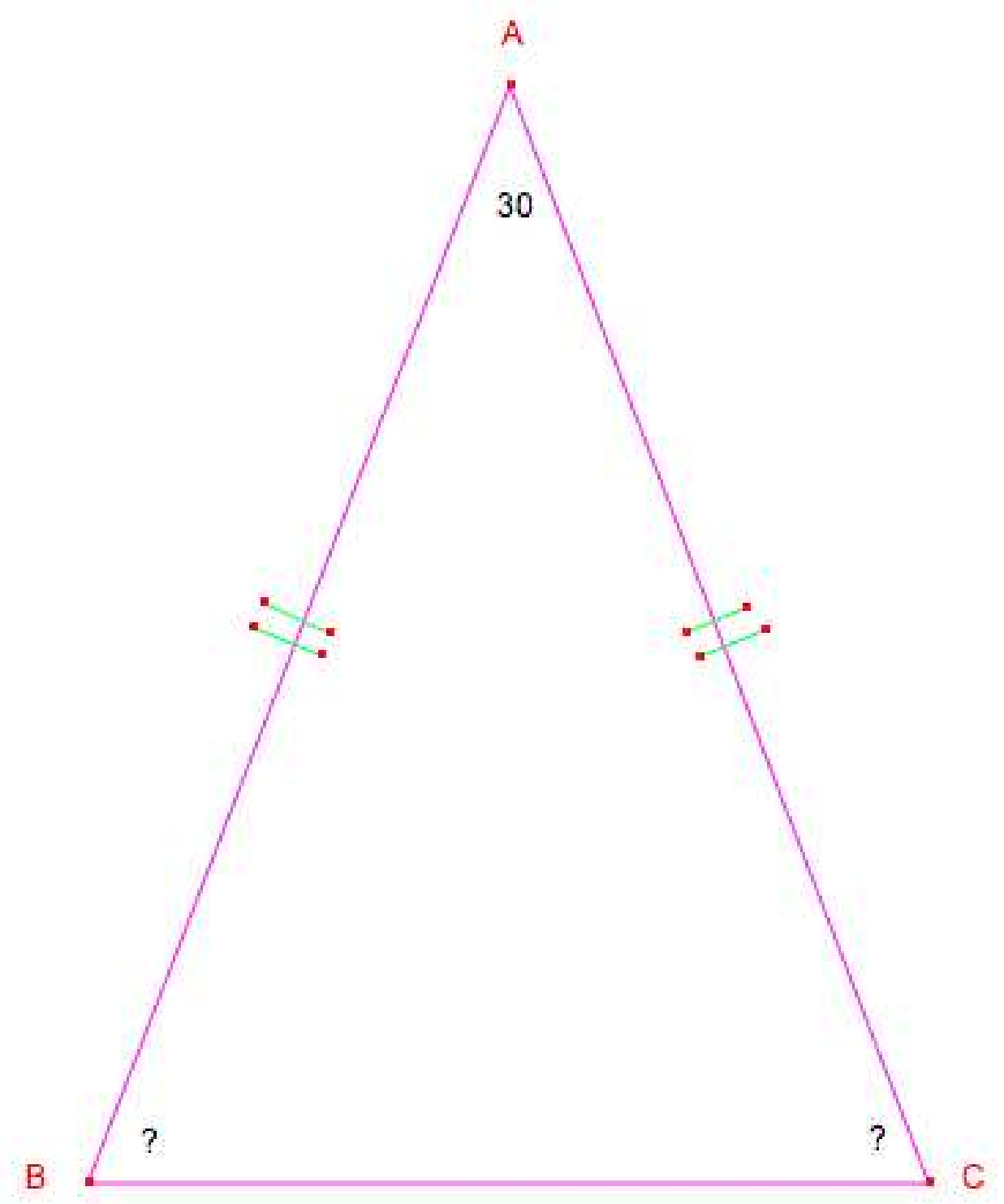


Similar test problem 2

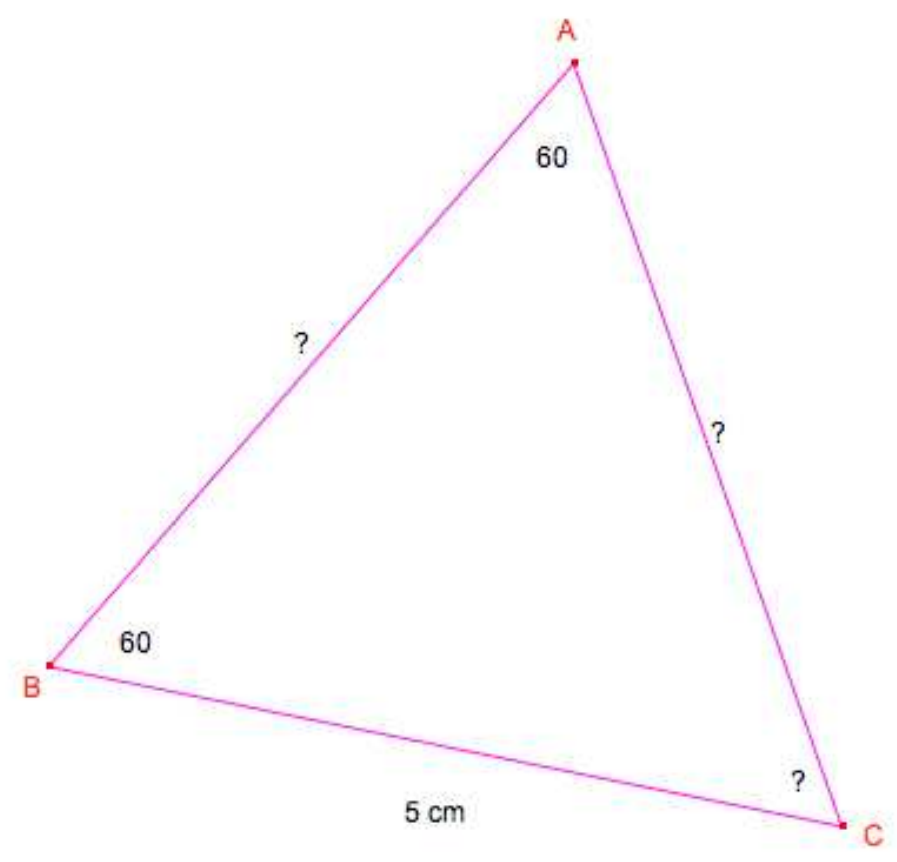


Similar test problem 3

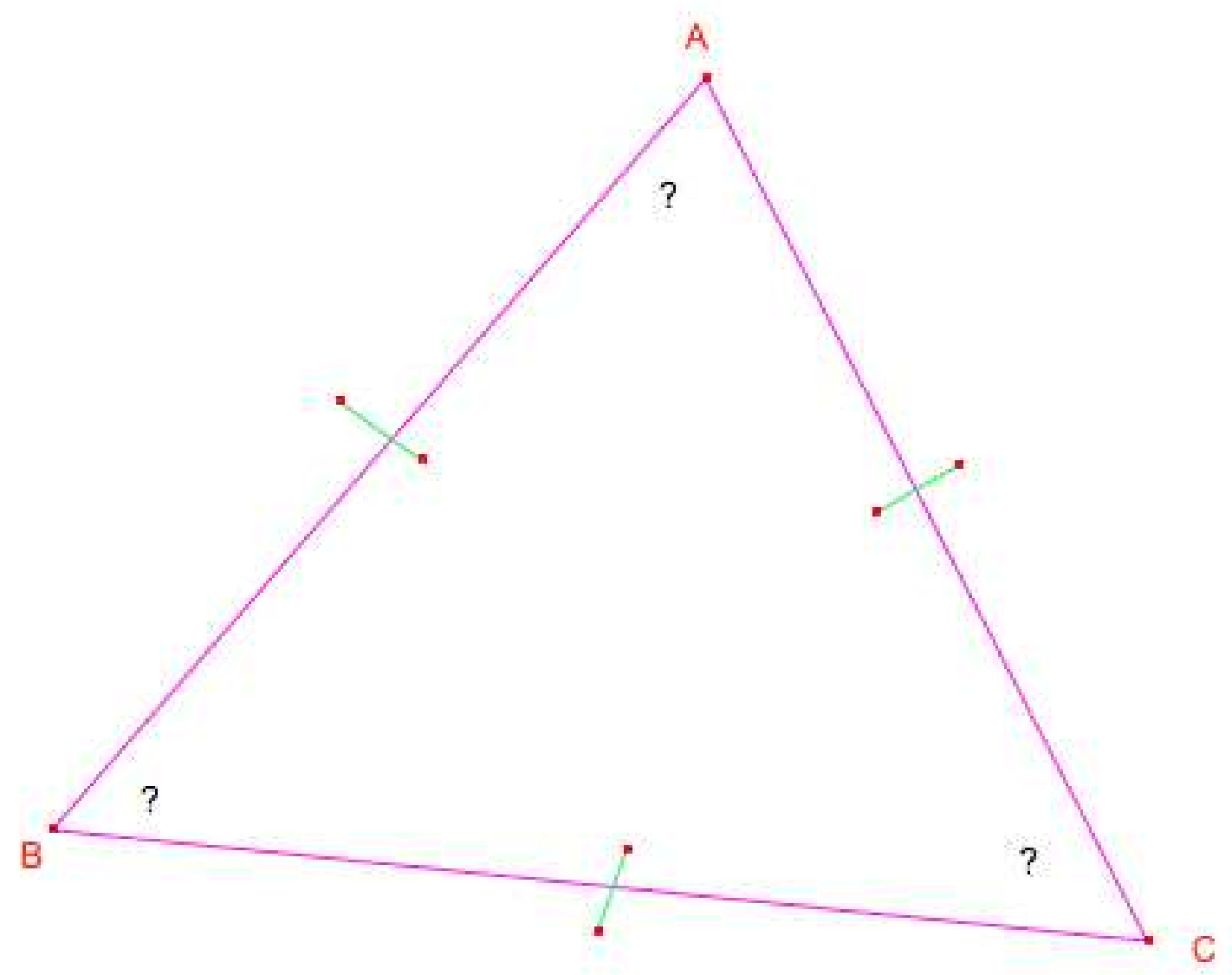


Appendix B

Transfer test material

Transfer test problem 1

Prove that $\mathrm{AB}=\mathrm{AC}=\mathrm{BC}$

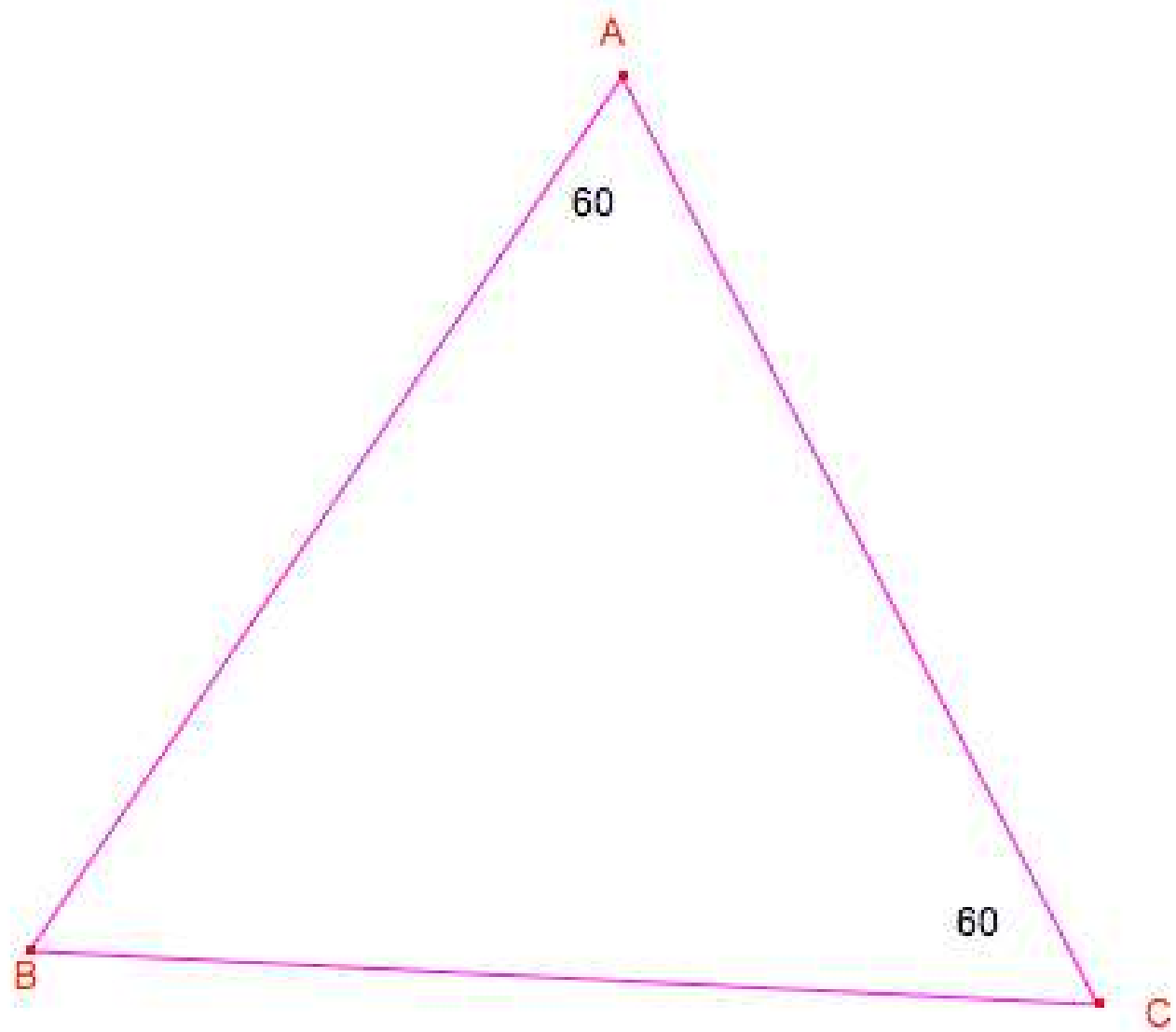




\section{Transfer test problem 2}

Prove that $\mathrm{ABC}$ is an isosceles triangle

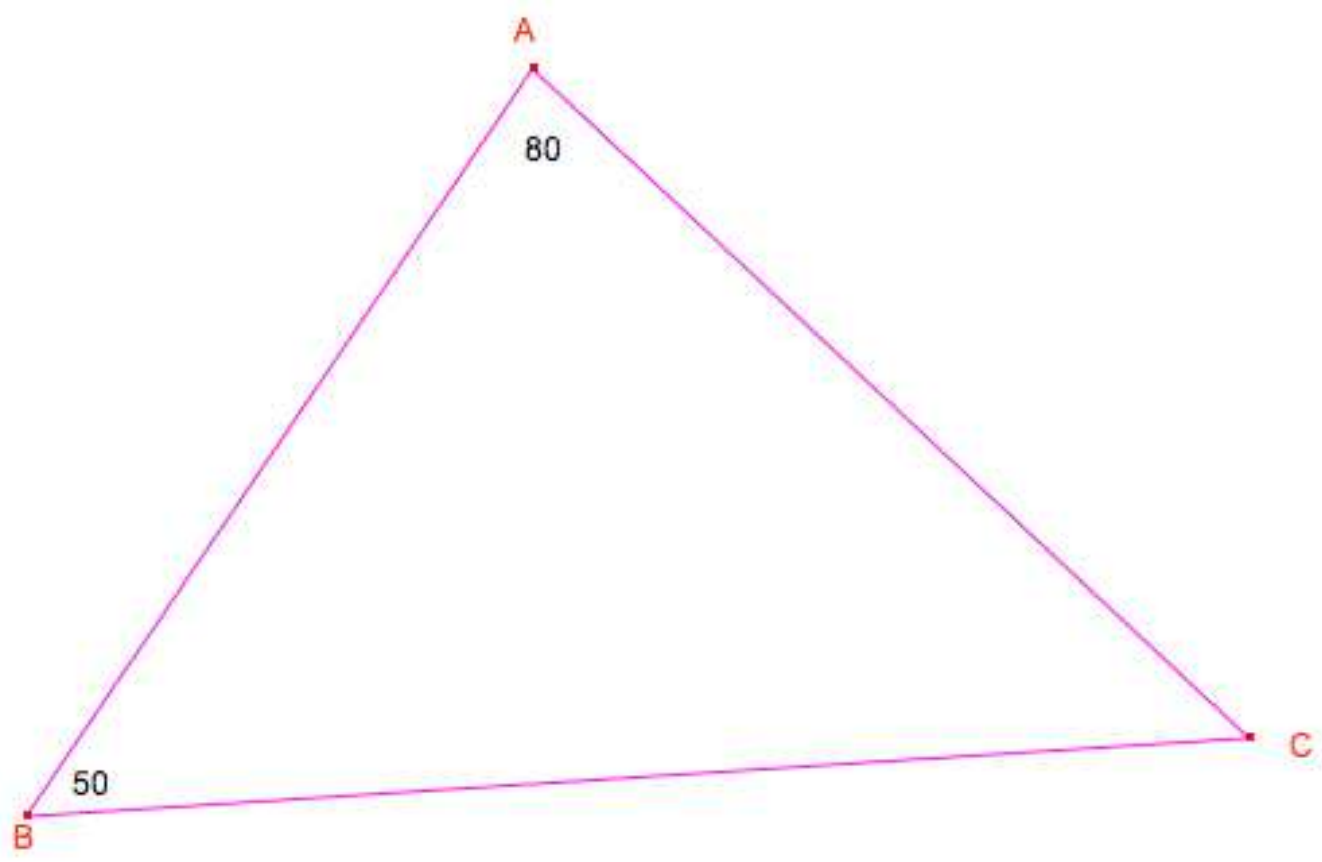




\section{Transfer test problem 3}

Prove that $\mathrm{ABC}$ is an isosceles at $\mathrm{B}$

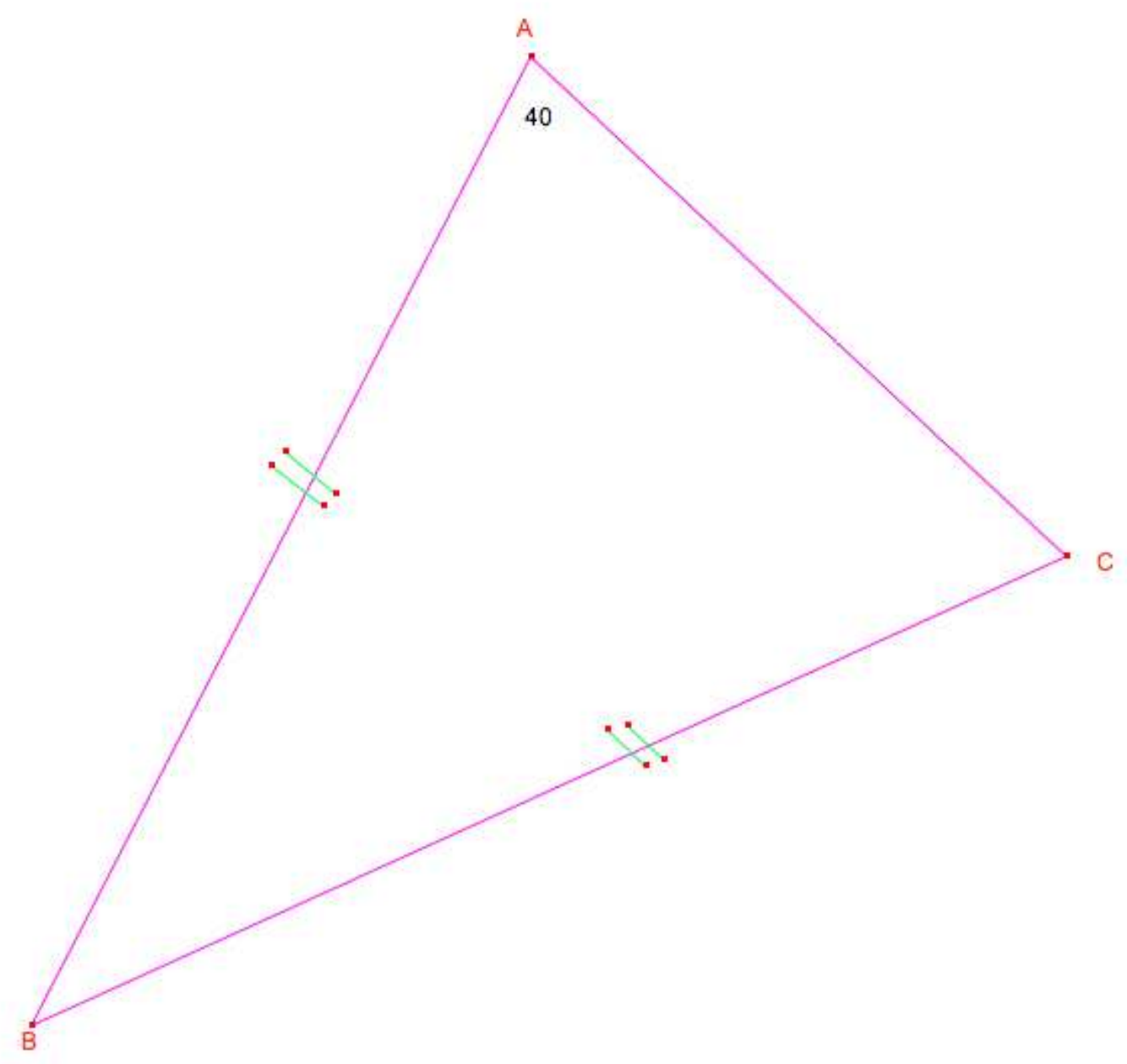




\section{Appendix C}

\section{Cognitive Load Rating}

How easy or difficult did you find this task (tick one)

\begin{tabular}{|l|l|l|l|l|l|l|l|l|}
\hline 1 & 2 & 3 & 4 & 5 & 6 & 7 & 8 & 9 \\
Extremely & Very & Easy & Slightly & Neither & Slightly & Difficult & Very & Extremely \\
& Easy & & Easy & Easy & Difficult & & Difficult & Difficult \\
& & & & Nor Difficult & & & & \\
& & & & & & & & \\
\hline
\end{tabular}


Highlights

- Learning of cognitive tasks can be supported by observing or making manipulations

- Manipulations are evolutionarily salient skills that require low working memory load

- Low memory load enable new information to be processed within the limited capacity of WM 